\title{
Review of the feed industry from a historical perspective and implications for its future
}

\author{
D. Coffey ${ }^{1}, \mathrm{~K}$. Dawson $^{1}$, P. Ferket ${ }^{2}$ and A. Connolly ${ }^{1 *}$ \\ ${ }^{1}$ Alltech Inc, Nicholasville, KY USA \\ ${ }^{2}$ Prestage Department of Poultry Science, North Carolina State University, Raleigh, NC USA
}

\section{Summary}

The history of the feed industry is pertinent in terms of understanding how and why certain practices have evolved. Some of these practices have been superseded by modern, more natural alternatives, for example the traditional use of antibiotics in feed. In other cases, such as inorganic minerals, more natural versions akin to those found in plant and animal materials are available, although these new initiatives are still being taken up globally. Research continues to increase our knowledge and understanding of nutrient balance and digestion, and in some species this is more advanced than others. The following paper represents the first complete history of the feed industry, its major milestones, and projects how it might continue to utilise new technology developments to improve animal feeding practices.

Keywords: history: feed industry: regions: future

(Received 8 July 2015 - Accepted 24 September 2015)

\section{Introduction}

Nobody knows when deliberate animal feeding systems developed, as it happened before the advent of writing. Techniques of animal husbandry developed spontaneously some 12,000 years ago in several areas of the so-called 'Fertile Crescent', an ancient area of early human civilisation stretching between Mesopotamia, Assyria and across to Egypt. The ability to create a stable food supply from animals allowed the world's population to grow, residential centres to develop and cities to emerge. The domestication of wild crops and livestock, and the introduction of irrigation and the plough meant that there was enough to feed a world population of over 200 million by the time of the birth of Christ. As the human population grew and societies became increasingly urbanised, plant and animal agriculture became more organised, efficient, and productive, with periodic game-changing advancements in technology and innovation. Once animal production practices transitioned from free-range grazing to confined housing, and animals were bred for better productive performance, providing them with a 'nutritionally balanced' diet became necessary. Changes in agricultural production practices begun in the $18^{\text {th }}$ century culminated in better approaches to overall animal feeding at around the turn of the $19^{\text {th }}$ century. As a result, a constantly evolving feed industry was born.

\section{Scientific approaches to nutrition}

Nutrition became a scientific discipline primarily during the last 200 years. In 1810 a German scientist named Albrecht Daniel Thaer developed the first feed standards by comparing potential feedstuffs to meadow hay and assigning a 'hay value' as a comparative measure. About 50 years later, the Weende Experiment Station in Germany devised the 'proximate analysis system', which allowed feed to be analysed for certain defining characteristics which were used to determine crude fibre, nitrogen (and hence crude protein by calculation), ash and moisture - which, although rather limited in 
usefulness, remains in place as a system for basic comparisons of nutrient value in feedstuffs today ("proximate analysis'). These German scientists introduced reproducible and mathematical means to assess nutritional value based on chemical analysis of feedstuffs. In 1864, Dr. E. Wolff paved the way for the first feed standards based on digestible nutrients, and W.O. Atwater brought the Wolff standards to the attention of American researchers in 1874, which were then published in 1880 by H.P. Armsby in his book entitled 'Manual of Cattle Feeding' (Schoeff et al., 2005; Armsby, 1908). These feeding standards were adapted by C. Lehman in 1897 and were published a year later by W.A. Henry in the first edition of his book 'Feeds and Feeding' (Henry, 1898). These standards were further modified in the 1915 edition of 'Feeds and Feeding' by W.A. Henry and F.B. Morrison to express the requirements of animals and the composition of feeds in terms of digestible protein and total digestible nutrients (TDN), the latter as a combined value for the useful energy from carbohydrates, fats, and protein (Henry and Morrison, 1915). From the 1920s to the 1940s, considerable information was published on the mineral and vitamin requirements of various animal species, but none were considered in feeding standards until 1942, when L.A. Maynard directed the Committee on Animal Nutrition of the National Research Council in the U.S. to form subcommittees to prepare nutrient requirement tables for farm and laboratory animals. These were first published in 1944 and subsequently updated as deemed necessary. NRC nutrient requirements are now used as a global standard for formulation and research and are available for poultry, swine, dairy, beef cattle, sheep, goats, horses, rabbits, dogs, cats, mink and foxes, fish and laboratory animals.

\section{Early developments in animal feed production}

The first use of ground grain for animal feed was recorded as early as 1813, but grinding grains for livestock was only a secondary purpose of early mills. Originally mills were in place for grinding grain for human consumption, and the leftovers were naturally thought to have potential feeding value for livestock and poultry. Oats were traditionally used for animal feeds, especially equine, as they were cheap to grow and had much less use in human food compared to wheat. The end of the $19^{\text {th }}$ century marked a culmination of events that put the industrialisation of animal feed into force. The industrial revolution had already ignited growth in grain milling, meat packing, and milk processing. The concurrent increase in milling waste that was being dumped into water sources quickly gained negative attention and was halted by governmental law.

During this time the benefits of a balanced diet in animal production were being realised. There was an immediate need to redirect by-products from human food production to avoid waste build-up and to substantiate complete feeds. When chemical analysis of such grain by-products proved their nutritional value, the commercialisation of the modern feed industry was initiated. Today, these by-products are more appropriately defined as co-products of grain and animal processing, using technologies that extract nutrient and energy value.

The first commercial opportunity for formulated feeds, as we would recognise them today, arose in the early 1800s when horses and mules supplied the main form of transportation and energy to drive agricultural equipment. The network of livery stables that supplied feed and rest for horses were almost as common as service and gasoline stations are today (Schoeff et al., 2005). Good feed for horses and mules was in high demand, and many of the largest feed companies in existence today (e.g. Cargill, ADM, Purina Mills, and Ridley) started out by producing horse and mule value-added feeds, although very little scientific feed formulation or manufacturing was involved.

Manufacturing formulated feeds based on the first feed standards started in the late 1800s. In 1870, the first batch mixed feed was reported in Massachusetts, but it was only after the first animal nutrition books were published by Armsby and Henry in the 1880s that the industry took off as a whole. The first corn gluten was manufactured in 1882 and Cargill, who had primarily dealt in flour milling, entered the animal feed industry just two years later in 1884. In the mid 1800s sociologists such as Mayhew (1851) were writing about the 'cat meat men' present in major cities such as London, who purveyed mostly horsemeat to households for their pets. In 1890 meat scraps were one of the first by-products to be recognised for their superior nutritional value and adopted by the emerging commercial feed industry. The 1890s also introduced the incorporation of brewing by-products into animal feed and saw the start of Purina Mills in 1894 (Pederson, 2000).

\section{The U.S. feed industry}

All aspects of feed manufacturing advanced rapidly at the advent of the $20^{\text {th }}$ century. The intensification of the 
food system initially involved the development of dedicated farming units, but the introduction of synthetic fertilisers in the 1900s allowed for control of nitrogen levels in soil and significantly advanced farm productivity. This allowed greater specialisation and dramatic increases in crop yields, which in turn led to increased livestock production. The feed industry, and agriculture overall, began to embrace more advanced technologies and mechanisation in pursuit of feed uniformity and efficiency. In the years leading up to 1900 the first hammermill was used, followed by the horizontal batch mixer in 1909. The first quarter of the $20^{\text {th }}$ century saw rapid evolution in the mill, but the entire industry was revolutionised when Purina introduced pelleted feed in the 1920s. This method was used to compress fine, unpalatable, variable density and difficult feed materials into easier-to-handle pellets with increased uniformity, and was rapidly adopted by other manufacturers. By the 1930s there were many feed mills which specialised in pellet production.

In the U.S. feed mills had been traditionally located in cities like Chicago or Minneapolis for their proximity to grain mills. Companies already in the milling industry were heavily involved in the feed industry as a means to utilise grain processing by-products as an alternative to disposing of them. The early feeds were made by adding nutrients to basic flour by-products. However, the 1940s and 1950s marked a time when formulations became more complex as essential trace minerals were identified, synthetic vitamins were developed, and the addition of antibiotics came into practice. Simultaneously, the feed industry began to expand beyond the original flour milling companies, with hundreds of firms entering the feed business; the total number reaching more than 2,000. Moving away from the original hubs, smaller feed mills accomplished the new complex diet formulations with batch mixing and were in locations closer to the farm. This transition was important in terms of opportunities for specialisation, as was the introduction of extruded pet food later in the mid 1950s.

By the end of the 1950s advancements and specialisation had continued to favour a trend of consolidation in the feed industry. Transitioning to the 1960s and 1970s involved the construction of very large feed mills, so that the norm became plants capable of producing 200-500,000 tonnes annually. Relocated to large sea ports, grain terminals and along rivers and railway lines, these mills were only limited by the costs in shipping raw materials and distributing finished product.
However, cattle feedlots and other large farms chose to install their own feed mills in efforts to become more competitive.

Meanwhile, farm technologies such as fertilisers, chemical pesticides, antibiotics and hormones became commonplace. The growth of the feed industry led to increased consolidation of farms, which took advantage of economies of scale in production. At the same time, the number of farms diminished, while the size of the remaining farms increased and resulted in overall increased productivity. In fact, from 1950 to 2000 the number of U.S. farms decreased from 5 million to 2.2 million.

Consolidation is not the only industry trend that has continued to date in the U.S. Enhanced automation of the feed mill began in 1975 and has since evolved to minimise feed cost per unit of animal produced and maximise the efficient production of feed. Since the first automated feed mill, the technology and software behind processing have continued to improve ingredient receiving logistics, ground ingredient particle size characteristics, batching and mixing, pellet processing, extrusion processing, post-pellet applications, process control, feed delivery logistics and many other facets of manufacturing (Ferket and Stark, 2011). Over the last 50 years, technology has diversified so that production can be even more automated while allowing specialising for a given feed mill's goals. More recent advances in equipment include liquid applicators in 1990, the overall computerisation of operations, NIR in-line nutrient analysis and data collection in the feed mill.

\section{European feed industry}

The European feed industry emerged in a way and time that mirrored much of what was happening in the U.S. As early as the $17^{\text {th }}$ century, European farmers were utilising manure, crop rotation and cover crops technologies to increase crop yields. Guano and bone meal from the emerging colonies were increasingly available for agricultural use.

Grain processing and mill technology advanced rapidly in the $19^{\text {th }}$ century. The first compound feed was thought to have been used by the British as transportable nourishment for horses during wars. Resembling a large baked biscuit, this feed was a combination of meal from oat, peas, rye, flax, wheat or maize. According to feeding experiments done by the Prussian army, $33 / 8 \mathrm{lb}(1.53 \mathrm{~kg})$ 
of this first compound horse feed could substitute for 11 pounds (5 kg) of oats (Kariger, 1963). The roller mill debuted in Switzerland in 1830 and improved as it spread throughout Europe in the coming decades. By 1877 it had become a tremendous innovation in grain processing and agriculture overall; the number of roller mills in England increased from one in January to 350 in December of the same year (Farrer, 2005). In the mid 1800s the introduction of properly balanced proteins and starches was shown to have the potential to increase the quality of meat, milk and eggs. The strides made in agriculture leading up to the late $19^{\text {th }}$ century began to reveal the value of nutrition in increasing animal performance and the profitability therein. Producers and nutritionists started to experiment with formulation and, for the first time, began to design feeding for predetermined results in terms of performance.

Oil seed crushing was already a significant contributor to the feed industry, with oil cake being a large constituent of animal feeds early on. However, the rapid industrialisation of various sectors throughout Europe in the later $19^{\text {th }}$ century produced mass quantities of other by-products that found their way to the feed industry (Dean, 1996). With raw materials and equipment already in hand, the emerging feed industry provided an open door to companies already invested in processing grain.

The early $20^{\text {th }}$ century was rapid in feed innovations. Inconvenient oil cake slabs were replaced by feed that was more appropriate for direct feeding. Pelleting was as revolutionary in Europe as it was in the U.S., rapidly becoming the most popular form of feed.

In 1959 Belgium, France, Germany, Italy, and the Netherlands formed the European Feed Manufacturers' Federation (FEFAC) as an umbrella organisation for the European feed industry. FEFAC is in place to unify the industry and initiate communication and cooperation across E.U. countries where industry regulation is concerned. Since 1959 FEFAC has successfully piloted the European feed industry through a variety of issues, but 1996 marked the most trying obstacle (FEFAC, 2009). The 1996 Bovine Spongiform Encephalopathy (BSE) crisis in the E.U. was linked to the inclusion of mammalian meat and bone meal (MBM) in ruminant feed. BSE infected meat was associated with Creutzfeldt-Jakob Disease in humans, and thus posed an enormous risk in the food chain. Following the outbreak, the E.U. suspended the use of MBM, but in 2001 the use of MBM was banned from animal feed altogether. These regulations resulted in heavy dependence on raw material imports such as soybean meal to sustain Europe's supply of meat, milk and eggs. Moving forward, FEFAC and the industry were, and continue to be, heavily focussed on sustainability in order to restore self-reliance.

The European feed industry of the $21^{\text {st }}$ century is known for its initiatives in feed and food safety. They set the pace internationally, with the 2001 ban of MBM, the 2006 ban on antibiotics in feed, regulatory legislation regarding nitrate in animal waste and the use of genetically modified organisms (GMO). Individual countries within the E.U. lead international discussions on the global feed industry's challenges and opportunities. Denmark, for instance, is the world leader in antibiotic surveillance and risk assessment, while the Netherlands pioneered 'gas washing' as a method of cleaning livestock gas emissions. As outside countries now face major regulatory decisions, the E.U.'s experience with regulation, agribusiness and food safety will likely become the industry model.

\section{Brazil}

Although Brazil is now the third largest supplier of world feed, commercial feed production has only been common within the country since 1960 . The emergence of the Brazilian feed industry followed the same model as the U.S. and Europe; those companies involved in the milling and processing of wheat, corn and barley being the first to be involved in animal feed. The first feed mills made animal feed from wheat bran in the 1940s and these initial feeds were sold as processing byproducts, which were mixed into complete feeds.

The first true example of a commercial feed came from the Agricultural Cooperative of Cotia which, in 1941, built a feed mill in Sao Paulo to meet the demands of the developing egg layer business. Over time as the business grew, so did the demands for feed and this was met by the cooperative's feedmill. Brazil's other hugely successful integrated meat producers, principally broilers and pigs, also required high production levels of feed. Today, 99\% of broiler feed is integrated with production companies, as is most of Brazil's swine feed, although not to the same degree. This level of integrated production means that $80 \%$ of Brazil's feed production is manufactured by the same company that will feed it to their animals.

Many of the Brazilian feed companies are linked to one another. For example the Mogiana/Guabi Company was founded in 1974 by former employees of Purina. In the 
late 1980s they had developed a substantial premix business that surpassed Purina in feed production. In the 1990s the executives from Mogiana/Guabi left to form Nutron. Subsequently the executives left Nutron several years after it was acquired by Provimi to establish further feed, premix, and pet food companies.

Brazil has seen substantial growth in aquaculture feed and pet food production. Today, the Brazilian pet food business is the second largest by volume in the world. This industry was almost non-existent before the 1990s. Enabled by a dramatic fall in price for food products in the 2000s, the expansion of the middle classes, and imported extrusion technology, Brazil's pet food market has grown 25 fold within the last 20 years.

Brazil has built its impressive feed industry by embracing modern technology in both equipment and zootechnical additives faster and more enthusiastically than any of the other major feed producing nations in the past 20 years. With a competitive advantage as one of the world's leading producers of cheap maize, soybeans and other commodities, Brazil's future as leading producer of animal feed is assured.

\section{China}

The feed industry in China has grown and consolidated at an unmatched rate relative to other regions. In 1930 the first modern flour mill began operation in China, allowing animal producers access to wheat bran. However, the first modern feed mill in China did not exist until 1949 (Hsu and Lopez, 2000). Subsequently, the years following were filled with political turmoil and stunted economic growth, and the centralised government limited grain production so that the majority was used in human consumption, limiting any potential for feed industry or livestock production.

A shift in Chinese policy in 1976 led to greater involvement in global trade and a willingness to adopt ideas and technology from the rest of the world. From this vantage point, compound feed and the milling industry were encouraged for the established benefits they could provide in animal production. A stronger feed industry could support livestock production that could increase both the economical standing of China and the health of its people. Up to this point there were virtually no feed mills in China, however, the industry had expanded to 14,000 feed mills by 1985. This count included small feed mills producing less than one tonne per hour (Hsu and Lopez, 2000). These feed mills were developed based on the needs of changing livestock production, and so became concentrated in provinces with major livestock sectors.

China's leaders made the success of the feed industry a priority for the country, with strategic directives starting in 1976. In 1977, China's first feed research institute was established and the following year the Ministry of Commerce assembled a team to study the already successful feed industries in France, Japan and the U.S. In 1984, a draft of the feed industry development plan was published to outline the goals and strategies set for 1984-2000 (Hsu and Lopez, 2000). That same year, with the intention to expedite the industry's expansion, the government ceased levying import tariffs on feedstuffs and milling equipment, gave three year tax breaks to new feed mills and allowed mills to be exempt from taxes based on profit (World Bank, 1993). These incentives were effective and the feed industry expanded vastly in this time. Specialist feed ingredients and supplements were introduced at a national conference in 1986, and the first 12 products were approved for use in 1987. Within a span of 10 years, mixed feed was all but phased out and compound feeds became the primary focus of the industry, with 62.99 million tonnes produced in 1997 (National Statistics China, 2014).

The first feed standards in China were published by the Ministry of Commerce in 1993, and by 1996 regulations had been established for compound and mixed feed, feed packaging, storage, and transportation. However, inconsistent interpretations of these regulations resulted in almost $10 \%$ of feed testing below standard in 1998 (Hsu and Lopez, 2000). In an effort to provide structure, the Feed and Feed Additive Regulation was enacted by the State Council LAO in 1999; and these, albeit with revisions, are still in place today (Enting, 2010). However, even with increased regulation, the new millennium proved to be a time of severe feed safety obstacles for China. The 2007 pet food recall was a major challenge to the industry, when melamine and cyanuric acid (which are high in nitrogen and used to give a false high calculated crude protein content) were found in protein components used in pet foods, causing kidney failure. Chinese companies claiming to sell wheat gluten, rice protein and corn gluten were inflating the protein content of wheat flour using the high N chemical compounds. Recalls occurred in South Africa, the E.U. and the U.S. and the USDA mandated the examination of all vegetable proteins for consumption imported from China (IBISWorld, 2015). Despite this, Chinese officials were slow to acknowledge the issue, but eventually allowed the U.S. FDA to inspect their 
facilities. Much of 2008 and 2009 were focused on eliminating protein adulteration and addressing the crisis that resulted. In 2010, a revised version of the Feed and Feed Additive Regulation was published with a clear initiative to closely manage animal feed production to improve quality and safety. Among other stipulations, the edited regulation specified a feed supply tracking system, evaluation procedures for new feeds and the refining of imported feed products (Enting, 2010).

Today, China continues to monitor food and feed safety while shifting their focus on becoming self-reliant (Cai, 2014). As a nation with a long history of famine and starvation, China is in pursuit of self-sustained food security and that starts with grain production and the feed industry. This can be seen with their recent dairy projects, whereby high genetic potential, in-calf heifers have been imported from major dairy producing countries, such as New Zealand. With such initiatives in place, grain production has risen steadily to reach 601 million tonnes in 2013, and the feed industry saw an annual growth of $15 \%$ from 2010 to 2015 to become the largest in the world (IBISWorld, 2015). However, they are still heavily reliant on imports and remain the world's largest user of DDGs and soybean meal in order to support 1.3 billion people with the necessary meat, milk, and eggs (Wan, 2014). Those imports are currently not of U.S. origin, after China's halt to all DDGs imports that have not been tested at origin for any unapproved varieties of grain. Chinese officials claim that this is a step towards 'China taking good control of its own bowl' by not permitting heavy dependence on western grain varieties, but rather developing their own (Blaustein, 2014).

\section{International Feed Industry Federation}

Founded in 1987 in Luxembourg by the then leading international feed associations, the IFIF was born from the need to better reflect the increasingly global nature of today's global feed business and its need for connectivity.

Today, this organisation represents over $80 \%$ of the global animal feed production and most, or all, of the industry's leaders and influential feed companies are present on its Board of Directors, either directly or through local associations. The IFIF Board includes representatives from the China Feed Association, the Brazil Feed Association, AFIA, FEFAC, Cargill, Nutreco, Alltech and DSM among others.

IFIF has played an instrumental part in conducting discussions to help ensure high standards of health and welfare for animals and people, by collaborating with the United Nations Food and Agriculture Organization (FAO), the World Organisation for Animal Health (OIE), the Codex Alimentarius Commission and other international bodies to help set international regulatory standards for the whole feed chain and support fair trade.

Given the anticipated growth of the world's population to around 9 billion people by 2050, and the associated higher demand for animal proteins including eggs, milk and meat, it is vital that we can meet this challenge in a sustainable and safe way. IFIF has engaged with the global feed industry to facilitate discussions about the central role of feed in issues of food safety and sustainability. In particular, the association has had a fourteenyear relationship with the United Nations Food and Agriculture Organization (FAO).

This ongoing relationship has resulted in a number of very successful initiatives, including the publication of an IFIF FAO manual about standards for good feed manufacturing. More recently, the FAO and IFIF have also been involved with initiatives to more accurately measure, benchmark and improve the sustainability of the livestock production chain and to analyze the role of antibiotics used in feed.

IFIF also aims to play a proactive role to promote sciencebased solutions and information sharing for feed manufacturers, consumers and regulatory authorities worldwide on a variety of issues that affect the supply of safe and affordable water and animal proteins such as beef, poultry, fish and dairy products, by facilitating global forums, such as the Global Feed \& Food Congress (GFFC) and the International Feed Regulators Meeting (IFRM).

\section{New ingredients and equipment}

From 1970 a variety of ingredients, equipment, and technologies have been developed to improve animal nutrition and feed efficiency. To improve animal performance by assuring adequate dietary balance for protein synthesis and meat production, the addition of essential amino acids began in 1977 with liquid methionine hydroxyl analogue, followed by dry DL-methionine in 1985, L-tryptophan in 1987, L-lysine monohydrochloride and taurine in 1989, L-tyrosine and L-arginine in 1990, and L-threonine during the late 2000s. The first use of ionophores in the 1970s and the development of premix (a uniform mix of micro-ingredients) further advanced feed quality and digestion. Other amino acids 
and supplements replacing antibiotics and other compounds were introduced to feeding later in the 1980s.

\section{Snapshot of today's feed industry}

The Alltech Global Feed Survey was established in 2011 to better estimate world feed tonnage and production trends. Now, with four years of data, there is a more accurate depiction of where the feed industry is today. Since the first survey, global supply of complete feed has grown to 980 million tonnes valued at $\$ 460$ billion, a substantial expansion from the 873 million tonnes and estimated $\$ 350$ billion in 2011 (Alltech, 2015). Over this four year timeframe, the greatest increase in production happened early on, as a myriad of challenges including drought, floods, high costs of raw materials, animal disease and fluctuating governance import/export standards has limited the industry to a modest growth in latter years (Alltech, 2014).

Regionally, Asia continues to be the largest contributor to world feed production, representing more than one third of the global supply. Initially Asia proved to be among the fastest growing regions, but lately growth has slowed to a more subtle increase. The number of feed mills worldwide has been estimated as being over 31,000 and more than half of those are found in Asia and North America alone. Africa and, more recently, Latin America were found to be the fastest growing regions with regard to number of feed mills and feed tonnage (Alltech, 2015). The largest average feed mill size, however, is found in the Middle East region, producing more than 63,000 tonnes on average per annum (Alltech, 2013).

China, Brazil, India and Russia (BRIC) are countries highlighted for their powerful entrance into the industry. These four countries represented a 33 million tonne increase in production by 2012, and India's favourable conditions and advancements have stimulated further growth (Alltech, 2013). Beyond the BRIC countries, the focus is on Turkey, Indonesia and Romania due to their substantial increase in production in 2014.

In terms of total feed tonnage, China is the world leader by a distinct margin, but since 2013 the country's feed industry has experienced a decline in both feed mills and feed tonnage, which is likely to have been driven by the government's preference for consolidation to increase traceability. Analysts attribute this decrease in production to suppressed consumer demands as a result of the slower pork market and avian flu (Alltech, 2015). These circumstances are a testament to the value of food safety and quality and its growing emphasis in China. More than ever, animal feed is being recognised for its integral role in the food chain and is perceived as a shared value and responsibility on a global scale. The U.S. and Brazil consistently rank second and third in feed production, reaching up to 172 million tonnes and 66 million tonnes respectively.

Poultry has sustained its position as industry leader with $44-46 \%$ of the feed market share, which is probably due to taste, perceived healthiness, flexibility in cooking use and religious preferences as well as its relatively low cost. Feed production for the pig sector has increased steadily since 2011 , even in the face of increased prices for raw materials. Ruminants, on the other hand, saw a decrease in market share, specifically in 2013, as high feed prices forced producers to utilise alternative feed sources (Alltech, 2014). The dairy sector has since shown recovery and increased its utilisation of compound feed, unlike beef producers who continued to exploit alternative sources into 2014. Changes in the value of milk products worldwide will dictate how the dairy sector's feed consumption varies in future. Aquaculture has seen tremendous growth since 2011, increasing market share by as much as $17 \%$ per year. The Food and Agriculture Organization of the United Nations (FAO) has released data indicating that trends in global consumption of farmed fish and shellfish exceeds that of beef on a weight basis. Finally, equine and pet foods continue to increase in tonnage, with equine peaking at $17 \%$ growth in 2012 . The U.S. has always been the world's major producer of pet food, but increases in household pet populations have positioned Brazil to expand into pet food at a rapid pace (Alltech, 2013).

The European region, and the E.U. in particular, have tried to stay ahead of the curve where food safety and quality are concerned. Most recently this region has experienced a decrease in overall production, especially for pigs and dairy cows (FEFAC, 2015). A steep decline in cattle feed production has been attributed to falling milk prices, suppressing the demand from farmers. Cattle and pig sectors are projected to continue to drop and Russia's ban on western imports threatens to stifle overall E.U. feed production. Most recently the European Commission College adopted the controversial proposal that nationalised GM crop imports for feed and food. E.U. organisations including COCERAL, 
FEDIOL and FEFAC say the possible bans on GM crops could be detrimental to the economy and could lead to a serious feed shortage (Irish Examiner, 2015). In other words, social climate and media opinion has reached a point where it poses a potential hindrance to efficient production (FEFAC, 2015). According to FEFAC president Alexander Doring, there are efforts emerging to revisit many E.U. regulations thought to have been developed in response to the crisis but which are now lacking relevance in today's feed industry.

As for the U.S., production of primary feed is led by the Corn Belt States (primary maize growing areas such as the mid-west), followed by the south eastern region. Animal to feed ratios given by the Feed Additive Compendium (2014), which compares the market value of a single animal to the price of feed, indicated that profitability due to feed costs increased from 2013 to 2014, suggesting a recovery from high 2013 feed prices (Feed Stuffs, 2014). Steers and heifers showed the greatest increase in profitability, followed by hogs and, while feed purchases by farmers have increased from 2008 to 2013, the overall feed price index has fallen significantly since 2012 .

The continued industrialisation of the feed industry has resulted in more tonnes produced by fewer feed mills. This consolidation trend is consistent in the E.U., U.S. and China; all of which have seen a substantial decrease in the number of feed mills, yet an overall increase in tonnage. Consolidation has been particularly favourable in China, as it assists in meeting food safety and traceability standards (Alltech, 2014).

\section{The future of feed}

The future of the feed industry will evolve based on a rapidly growing global population, changing socialeconomic climate, increasingly involved consumers and media and the constant pursuit for greater efficiency. The increase in population and GDP suggests demand for both cereal grain and meat protein will continue to increase. So, what might the future of the industry look like in order to accommodate these objectives? At this point, the cost of feed demonstrates a need for companies to re-evaluate and improve feed efficiency. Advancements in raw materials may result in novel feed stocks that change the entire approach to feed formulation. This is no longer a concern only for monogastric animals. Inexpensive feed options traditionally given to ruminants are limited and the future alternative is a carefully formulated feed aimed for greater efficiency in monogastrics and ruminants.

As the modern consumer has reached a new level of political and commercial involvement, there will be increased demands on the feed industry to stand accountable for their role in the food chain. As companies continue to be more consumer-oriented, so their focus on sustainability and their environmental footprint grows. Greenhouse gas emission and environmental impacts of animal production will all be considered, and will push feed mill and farm efficiency forward.

Consumers are becoming more selective in purchasing meat, milk and eggs, questioning what their animals eat and how they are kept. They see the feed mill as integral in the food chain and influencing human diet, which has now developed into a culture that wants to know exactly what medicines, practices, supplements and feedstuffs go into the animals they consume. Food safety continues to be a serious concern as today's feed may contain hazards, such as heavy metals, high dioxin levels, PCB's and mycotoxins. All of these toxins have the potential to enter the food chain via animal feed. Analytical systems have been developed to quantitatively and qualitatively detect the presence of such hazards in feed. Over time these methods will become more sophisticated and provide more rapid results, allowing the industry and government to react to ensure food safety. Food quality will continue to be a priority for many consumers and companies, putting it at the forefront of feed manufacturing. Concerns about food safety and quality at every stage in feed production will drive companies to be increasingly more transparent. Government regulations, such as the Food Safety Modernisation Act in the U.S. continue to enforce risk-based preventative animal feed safety systems.

\section{The information age and the feed industry}

In the future feed systems are likely to become even further intertwined with information technology, eventually allowing the flow of detail throughout the steps in the food chain whereby farm, feed mill, processing plant, retailer and consumer are connected. In this way, feed availability will be able to mirror demand and, in doing so, dramatically increase efficiency and reduce waste.

Widespread digitalisation will lead to on-farm measurements and monitoring done in real-time. This includes automated weighing scales sending continuous data on body weight, temperature and feed consumption for 
improving efficiency of animal production and welfare, while limiting waste. Systems in place for measuring environmental gases, excretion on land and other biological and chemical parameters will be useful in documenting the effects of nutrients on animal health, thus providing insight for necessary changes in diet strategy. Such measurements will also contribute to increased on-farm biosecurity.

As we look at new and more precise technologies to address nutritional challenges, it is clear that our views of nutrition, feed manufacture and feeding practices will continue to evolve. This will be reflected in the activities and structure of the global feed industry. It is possible to see these changes taking place today, as research and commercial applications focus more on modelling the dynamics of nutrient digestion, balance and utilisation, moving away from feeding practices based on the simple nutrient composition. As we develop more advanced technologies for controlling digestion and nutrient utilisation, traditional ways of formulating feeds based on compositional analyses will play a less important role defining feed formulation. These fine control mechanisms will be coupled with our ability to collect information about all aspects of the food chain and will define a new level of proactive precision feeding. It will be necessary to discard some of the time-honoured ways of describing nutritional value. This will open the door for the use of new feed ingredients, long-term nutritional conditioning and other novel supplement strategies. The outcomes will include improved production efficiencies, better maintenance of animals and more sustainable production.

Nutrigenomics is already being utilised in the development and understanding of certain nutrients, and is expected to provide standards for understanding both nutritional and environmental factors hindering production efficiency and welfare. Such information can allow a new level of precision in feed formulation and livestock production. Nutrigenomics is key in understanding the impacts of different nutrients on gene expression and provides the basis for more rational genetic selection. Subsequently, feeds will be closer to achieving genetic potential by targeting genes which are involved in animal growth rate, disease prevention and meat quality. Results from these studies will identify anti-nutritional activity and define feeding strategies that take advantage of the natural conditioning processes associated with prenatal and perinatal feed management practices.

The feed mill, itself, will become 'smarter', for example, with the use of NIR technology. This allows the analysis of incoming raw materials in real time, allowing reformulation of the diets on a minute-by-minute basis to ensure consistency of each batch manufactured. Additionally, rapid, in vitro digestion modelling systems will provide new ways of defining the true nutritional value of raw materials as well as the final feed products leaving the feed mill. These advanced systems can be used to define nutrient interactions and provide more accurate descriptions of nutritional values. Precision modelling and real-time decisions, resulting from greater amounts of information, will allow the feed industry to address issues associated with sustainability as well as minimise waste and the environmental impact from animal production. In the end, such technologies have the capability to provide a more objective feedstuff value for the interested buyer (Gill 2003).

Today, a typical western feed mill producing 100,000 tonnes of feed might involve the employment of three or less people. In a country like China, the same feed mill would require the labour of 45 individuals. This trend is expected to continue, whereby future feed mills become fully automated and a single person can effectively run a relatively large feed mill alone. As mill quality control systems continue to improve via automation for each of the different steps of production, traceability technology will allow larger volumes to be transported and tracked, while decreasing necessary labour. Not only does this provide a greater level of efficiency, but the increase in precision and data collection can then increase exponentially. In the future there is potential to apply artificial intelligence to analyse data and make immediate adjustments based on system inputs. Advancements are likely to occur in the pelleting process, so that what is now considered an art might become more of a science. By controlling more of the parameters involved in pelleting and cooling there is opportunity to reduce costs, improve feed quality and assure food safety.

\section{Key ingredients}

The rate at which any of the aforementioned solutions are adopted by the industry is dependent on the challenges it faces. The immediate approach of the feed industry, however, is to improve animal performance characteristics, minimise costs, and maximise feed production efficiencies. Above all, digestibility and FCR require attention. Novel ingredients continue to be explored for their capacity to effectively improve FCR. Once identified and developed, such ingredients become 
necessary inclusions in diet formulations, especially in situations when the efficiency of each point of feed conversion becomes increasingly valuable.

One possible ingredient that could become commonplace to feed formulation is algae: a source of protein, oils, pigments, vitamins and starch. Emerging technology positions algae to become a major, nutritionally-rich biomass and it is already known as a prime source of omega-3 fatty acids. Initial trials utilising algae produced results showing improvements in both reproductive performance and nutritional value of meat. Solid state fermentation (SSF) is an ancient technology that, with new techniques and applications, can be used for growing enzymes directly on feedstuffs. SSF makes it possible to produce a custom enzyme cocktail that can be used for improving digestion of feed stuffs, which enhances animal health, performance and profitability. The process involves growing a specific strain of Aspergillus fungi directly on feed, which gives a substrate-specific array of enzymes which aid in the digestion of fibre and other nutrients to a degree that has never been accomplished with traditional, batch fermentation methods. Data from trials in poultry, pigs and aquaculture have shown improved digestion and significant potential savings as a result of including such products in feed.

\section{Conclusions}

The future focus of the feed industry will be to verify their ability to meet consumer demands of safety and sustainability, while becoming more efficient and productive in order to feed the nine billion people estimated to be alive globally in 2050. Consolidation of the existing 31,043 feed mills will continue, probably seeing numbers halve in the next ten years. Advanced technologies will increase automation and real-time measurements so that verification is not dependent on the honesty of the supplier. Transparency, traceability and responsibility will become a cornerstone of the industry. Analytical technologies, such as NIR, advanced in vitro fermentation modelling, nutrigenomics and bioinformatics will intervene in feed formulation so that nutritional value is defined and feed formulation and manufacturing is no longer an 'art' but a more precise science. Similar technologies will be in place to detect contaminants and allow a new level of food safety. To achieve increased animal performance while minimising feed costs, new nutritional strategies, such as novel raw materials and feed additives, must be employed to optimise feed conversion and digestibility.

\section{Acknowledgments}

This paper was based on a presentation by A.J. Connolly to the 2013 China Feed Industry Association meeting in Beijing. No funding was received.

\section{Declaration of Interest}

A. Connolly, K. Dawson and D. Coffey are employees of Alltech Inc.

\section{References}

Alltech. (2013) Global Feed Survey Summary. Alltech internal research report http://www.alltech.com/sites/default/files/2013-feed-tonnagereport.pdf

Alltech. (2014) Global Feed Survey Summary. Alltech internal research report http://www.alltech.com/sites/default/files/alltechglobalfeedsummary2014.pdf

Alltech. (2015) Global Feed Survey. Alltech internal research report http://www.alltech.com/sites/default/files/global-feed-survey-2015. pdf

Armsby H.P. (1908) In: Principles of Animal Nutrition. (3 ${ }^{\text {rd }}$ edn.) John Wiley and Sons, Inc., New York, N.Y., pp. 312-315.

Atwater W. O. (1874-1875). Results of late European experiments on the feeding of cattle. Connecticut Board Agricultural Annual Reports, 8:131.

Blaustein L. (2014) Hit us where it hurts: China's ban on U.S. agricultural products grows. Retrieved June 18, 2015, from http://www.chinalawblog. com/2014/08/hit-us-where-it-hurts-chinas-ban-on-u-s-agriculturalproducts-grows.html

Cai H. (2014) Past and the future of the China feed industry. Presentation at Symposium, marking 20 years of Alltech in China, Beijing.

Dean R. (1996) Feed Industry Review: A structural and financial analysis of the $U K$ and European animal feed industries. London: Simon Mounsey.

Enting I., Wang B. and Zhang X. (2010) The Animal Feed Chain in China Opportunities to Enhance Quality and Safety Arrangments. Ministry of Agriculture, Nature and Food Quality.

European Commission. (2001) Common position on animal byproducts regulation agreed MBM-ban will be prolonged [Press Release]. Brussels, Belgium.

Farrer K. (2005) To feed a nation a bistory of Australian food science and technology. Collingwood, Vic., Australia: CSIRO Pub.

Feed Stuffs. (2014) Feed Marketing and Distribution in: Feed Additive Compendium (pp. 3-18). MN.

FEFAC, FEDIOL and COCERAL (2015) Joint Statement from COCERAL, FEDIOL and FEFAC on Commission nationalisation proposal [Press Release]. Retrieved from http://www.fefac.eu/files/ 59964.pdf

FEFAC. (2009) FEFAC $50^{\text {th }}$ Anniversary. Brussels, Belgium.

Ferket P. and Stark C. (2011) Recent Developments in Feed Technology. North Carolina State University Dept of Poultry Science report.

Gill C. (2003) Grain grading going digital. Feed International 23: 6-9

Henry W.A., and F.B. Morrison, (1915) Feeds and Feeding. HenryMorrison Co., Madison, Wis., $15^{\text {th }}$ ed.

Henry W.A. (1898) Feeds and Feeding. W.A. Henry, Madison, WS, USA., p 171.

Hsu H. and Lopez M. (2000) China. USDA publication, Washington, USA.

IBISWorld. (2015) Animal Food Manufacturing in China: Market Research Report. Retrieved June 18, 2015, from http://www.ibisworld.com/ industry/china/animal-food-manufacturing.html

Irish Examiner (2015) Animal feed groups seek GM clarity from European Commission. Retrieved June 3, 2015, from 
http://www.irishexaminer.com/farming/news/animal-feed-groupsseek-gm-clarity-from-european-commission-311930.html

Kariger A. (1963) The development of the compound feed industry in Germany. In: Publications of the Higher School of Economics Mannheim, Row 1:: Essays, Book 11. Retrieved June 1, 2015, from WorldCat.

Mayhew H. (1851) In: Labour and labouring classes. London Spring Books, UK.

Maynard L.A. (1944) The Atwater system of calculating the caloric value of diets. Journal of Nutrition 28:443-452.

National Statistics China (2014) China statistical yearbook. Chaine Statistics Press.
Pederson J. (2000) Purina Mills, Inc. History. In International directory of company histories. Vol. 32. Detroit, Mich.: St. James Press.

Schoeff R.W., Fairchild F.J., Bursiek B. and Castaldo D. (2005) History of the formula feed industry. In: E.K. Schofield (Ed.) Feed Manufacturing Technology $V$. American Feed Industry Association, Arlington, VA, USA.

Wan F. (2014) The Quest to feed China: First, feed the animals. Forbes Magazine, Forbes Inc, USA. October 21.

World Bank (1993) China: Animal feed sector study. World Bank Publications, Washington, D.C., USA. 